\title{
Cécile Alduy, Politique des «Amours». Poétique et genèse d'un genre français nouveau (1544-1560)
}

\section{Dario Cecchetti}

\section{(2) OpenEdition}

1 Journals

\section{Edizione digitale}

URL: http://journals.openedition.org/studifrancesi/9159

DOI: 10.4000/studifrancesi.9159

ISSN: 2421-5856

\section{Editore}

Rosenberg \& Sellier

\section{Edizione cartacea}

Data di pubblicazione: 1 juin 2008

Paginazione: 174-175

ISSN: 0039-2944

\section{Notizia bibliografica digitale}

Dario Cecchetti, «Cécile Alduy, Politique des «Amours». Poétique et genèse d"un genre français nouveau (1544-1560)», Studi Francesi [Online], 154 (LII | I) | 2008, online dal 30 novembre 2015, consultato il 10 janvier 2021. URL: http://journals.openedition.org/studifrancesi/9159 ; DOI: https://doi.org/10.4000/ studifrancesi.9159

Questo documento è stato generato automaticamente il 10 janvier 2021.

\section{(c)}

Studi Francesi è distribuita con Licenza Creative Commons Attribuzione - Non commerciale - Non opere derivate 4.0 Internazionale. 


\title{
Cécile Alduy, Politique des «Amours». Poétique et genèse d'un genre français nouveau (1544-1560)
}

\author{
Dario Cecchetti
}

\section{NOTIZIA}

CÉCILE ALDUY, Politique des «Amours». Poétique et genèse d'un genre français nouveau

(1544-1560), Genève, Droz, 2007 («Travaux d'Humanisme et Renaissance», n. CDXXII), pp. 597.

1 Tra il 1544, data della pubblicazione della Délie di Scève, e il 1560, data della prima pubblicazione delle Euvres di Ronsard, in cui le Amours compaiono nel primo tomo commentate e suddivise in due libri, si passa da una problematica della raccolta di poesie amorose all'inserzione di questa raccolta nelle CEuvres complete, il che, per quanto concerne Ronsard, «conferma lo statuto generico delle Amours, ma anche la loro funzione preparatoria d'esercizio di stile e il loro valore temporale di opere giovanili nella finzione biografica e poetica disegnata dall'ordinamento dell'opera omnia. Tale strategia editoriale istituzionalizza il titolo Amours come marchio di genere e situa questo tipo di raccolta allo stesso livello delle sezioni di Hymnes, di Discours o di Élégies come un genere particolare in seno a un sistema globale che riflette il contenuto delle Euvres. Integrandosi così nelle Euvres, le Amours perdono la loro preminenza come titolo autonomo. Acquistano in contropartita uno statuto di genere incontestato e una unità formale infine chiaramente delimitata» (pp. 25-26). C. Alduy, in una tesi di grande peso, diretta da un maestro degli studi sul petrarchismo quale Jean Balsamo, ricostruisce la nascita e l'affermarsi di questo genere e, soprattutto, la poetica che tale genere - quello appunto delle Amours - contraddistingue.

2 Studiando pertanto le Généalogies d'un genre (pp. 33-139) - alla ricerca di filiazioni e origini, ma allo stesso tempo facendo attenzione a non cadere in una causalità 
puramente meccanica - l'A. dimostra come nel costituirsi del genere Amours non vi siano né spontaneità generativa né filiazione univoca, ma si manifestino influenze incrociate e intertestualità: intertestualità peraltro polemiche, soprattutto per il fondersi di una tradizione nazionale, quella del recueil che sfocerà nel recueil marotique, con tradizioni importate dall'estero, quelle del canzoniere petrarchesco e dei canzonieri petrarchisti; con l'apparente paradosso per di più, caratterizzante il nuovo genere, di volersi servire di modelli stranieri per creare una letteratura nazionale. Pertanto, non la genealogia di un genere, quanto piuttosto le genealogie al plurale vengono qui studiate, ricostruendo da un lato le vicende della ricezione, in Italia e in Francia, dei Rerum vulgarium fragmenta (I, 1: Le 'canzoniere': une importation italienne, pp. 37-85), dall'altro ripercorrendo la storia dei florilegi poetici francesi fino a Marot (I, 2: Le recueil de poésie amoureuse en France avant 1544, pp. 87-116) e l'elaborazione del nuovo genere, che sarà quello delle Amours, tra la Délie e la prima edizione della raccolta ronsardiana (I, 3: Les enfances d'un genre: 1544-1552, pp. 117-139). Ma oltre che sulla Délie, sull'Olive, sulle edizioni delle Amours ronsardiane, C. Alduy concentra la sua attenzione su non meno di una trentina di raccolte di cui mette in luce la coerenza nelle tematiche, nella struttura generale e nel funzionamento sia a livello di linguaggio che di retroterra ideologico e 'politico', mostrando l'affermarsi di una poetica specificamente francese malgrado l'apparente derivazione dall'Italia. Infatti, se «lungo il percorso genealogico seguito in questa prima parte, è un genere specificatamente francese che si vede emergere, la cui funzione è proprio quella di proclamare la propria identità linguistica e di celebrare glorie nazionali per provare il valore del francese come lingua letteraria, tale genere realizza questo programma soltanto attraverso l'importazione e l'imitazione - infedele - di un modello straniero, le Rime di Petrarca, dalle quali riprende in particolare il mito e l'aura, ed anche l'unità lirica e narrativa, ma non la lezione morale, né lo schema di un'opera in due parti in vita e in morte» (p. 484). Se la prima parte del volume è consacrata alla genesi di un genere, la seconda (Genèse des cuvres: des textes au livre, pp. 143-307) studia il formarsi delle singole raccolte (con particolare attenzione oltre che all'olive di Du Bellay e alle Amours di Ronsard, alla Clarté amoureuse e alla Poésie di Le Caron, infine al Repos de plus grad travail e alla Suite du Repos di Des Autels come pure alla Continuation des Erreurs amoureuses di Tyard per quanto concerne il problema della 'continuazione'), evidenziando, attraverso l'analisi delle correzioni e dei cambiamenti cui Ronsard, Le Caron o Du Bellay sottopongono l'organizzazione interna delle loro raccolte, un ideale estetico della dispositio che «nelle arti poetiche, che si propongono nel Cinquecento una finalità più pedagogica che normativa, dovrebbe essere una categoria genetica, tecnica, di scrittura iscritta nel cuore di una creazione di cui si tratta giustamente di svelare le tappe, al fine di guidare il giovane poeta nella sua composizione» (p. 172). Nella terza parte (Poétique d'un genre, structure du texte, pp. 303-481), dopo lo studio diacronico della nascita del genere e del divenire delle singole raccolte, si passa allo studio sincronico del loro ordinamento interno, ricostruito nelle successive edizioni. L'A., qui, si pone il problema di come partendo da forme frammentate si possa giungere ad opere complesse ma unitarie e di quale sia il posto e il ruolo nel sistema letterario dell'epoca di un genere di successo, sì, ma che non ha ancora a monte una sistemazione teorica, anche se i codici nuovi stabiliti sono una realizzazione del programma collettivo della Deffence di Du Bellay.

3 Non è possibile in una scheda bibliografica di estensione limitata rendere conto della grande ricchezza di questo volume che contiene altresì un numero considerevole di 
analisi testuali minuziose e originali, e che, anche per gli annessi bibliografici, si dimostra un irrinunciabile strumento di lavoro. 